\title{
Intelligent plagiarists are the most dangerous
}

\section{How should we tackle the increasing problem of researchers rewriting others' results?}

Sir - In your News story "Plagiarism in Cambridge physics lab prompts calls for guidelines" (Nature 427, 3; 2004) and your Editorial "Complacency about misconduct” (Nature 427, 1; 2004), journals were criticized for not responding appropriately to plagiarism.

In my work as one of the editors of Physica Scripta, I have in recent years seen an increasing number of attempts at blatant plagiarism. For example, in 1973 I was one of five authors of a paper published in Physica Scripta (7, 241-249; 1973). Many years later an almost identical paper appeared in the Indian Journal of
Pure and Applied Physics (36, 273-279; 1998), where the main difference was that our names had been replaced by the names of two other authors.

However upsetting this may be, I believe that such naive plagiarism is not a significant threat to confidence in science, because such behaviour will ultimately have limited success.

What is worse, in my opinion, but was not discussed in these Nature articles, are cases where scientists rewrite previous findings in different words, purposely hiding the sources of their ideas, and then during subsequent years forcefully claim that they have discovered new phenomena. Such 'intelligent plagiarism' is, unfortunately, often more successful because most scientists do not have either time or sufficient interest to carefully investigate where the original results came from.

As such misconduct seems to me to have recently increased within the scientific community, I think that a thorough discussion of these issues, in Nature or elsewhere, is urgently needed.

Lennart Stenflo

Department of Physics, Umea University, SE-90187 Umea, Sweden

\section{Overseas scientists still welcome in United States}

Sir - I was pleased to see the headline of your Editorial "In praise of immigration" (Nature 427, 181; 2004). However, it was distressing to read the standfirst, which says "officials of the [US] federal government don't seem to recognize that the country's scientific strength depends in large part on foreign talent". Further, you go on to quote the National Science Foundation director, Rita Colwell, in support of this argument.

First, I must clarify that, although I am serving as chair of the National Science Board, the board has not yet had an opportunity to develop an official response to the Nature Editorial. However, I wanted to quickly provide my personal views to correct the potentially far-reaching and counterproductive impression conveyed by your Editorial.

Sadly, your Editorial seems to focus on a single, nine-word remark by Dr Colwell during a lengthy National Science Board press conference on the US scientific workforce. That remark, taken by itself, does not represent the view of the report presented by myself and other board members, including Dr Colwell. It is particularly frustrating that your article ignored a key theme of the Board's report (see www.nsf.gov/nsb/documents/2003/ nsb0369/nsb0369.pdf): the continued need for the United States to attract science and engineering students and professionals from other countries. This fact was stressed repeatedly during our presentation. Indeed, the National Science Board recommends that future US policies "while enhancing our homeland and national security, maintain the ability of the United States to attract internationally competitive researchers, faculty and students".
Your editorial gives the false impression that US science-oriented officials are unconcerned about the impacts on international students and professionals of US efforts to enhance homeland security in the wake of 11 September 2001. Nothing could be farther from the truth. The board has publicly stated concerns with the frustrating - and in some cases damaging — impacts on the lives of individual scientists and engineers, and on the overall US science and technology enterprise, from the security-driven changes in our treatment of all international visitors.

The National Science Board has worked and will continue to work with US science officials, with Congress and with the White House, to reduce the burden on science and engineering students and workers arising from our national security needs. In October 2003, the National Science Board asked representatives from the White House Office of Management and Budget and the US Department of State to attend a board meeting for the express purpose of discussing our concerns about current and future US visa policy (www.nsf.gov/nsb/ meetings/2003/nsb03138/nsb03138.htm).

We hope your readers recognize the commitment of federal science officials to ensuring that international researchers and students continue to feel welcome in the United States as partners in the US science and technology enterprise. At the same time, however, the federal government needs to take substantial steps towards increasing opportunities for US citizens to become more involved in science and engineering, in terms of both public awareness and potential careers that may directly or indirectly use these skills and knowledge.

Warren M. Washington

National Center for Atmospheric Research, 1850

Table Mesa Drive, Boulder, Colorado 80305, USA
HIV denialists will exploit any journal's tolerance

Sir - Richard Smith in Correspondence ("Milton and Galileo would back BMJ on free speech" Nature 427, 287; 2004) defends the rapid-response website section of the British Medical Journal (BMJ) — despite its use by those who deny that HIV is the cause of AIDS - on the grounds that free speech should always be allowed.

That's not the real issue, however. The 'HIV denialists' exploit the reputations of any bona fide scientific journals that publish their opinions, in whatever form. Will a member of the public always be able to appreciate the subtle distinction between a peer-reviewed publication in a journal and an informal posting on the same journal's website? One can readily imagine a layman (or even a head of state) being steered towards a BMJ rapidresponse posting and thinking "It's published in the $B M J$ - it must be accurate information".

The denialists crave respectability for their maverick opinions, and anything that energizes them to continue their efforts to damage science and public health is to be deplored. Let them exercise their right to free speech on their own websites, not on one run by a respected medical journal.

John P. Moore

Joan and Sanford I. Weill Medical College of Cornell University,

Department of Microbiology and Immunology, 1300 York Avenue, W-805 New York,

New York 10021, USA

\section{correspondence}

Contributions to Correspondence may be submitted to corres@nature.com. They should be no longer than 500 words, and ideally shorter. Published contributions are edited. 